\title{
Polymerization by Phase Transfer Catalysis IV. Polythiocarbonates by Polymerization of Diphenols with Thiophosgene ${ }^{\dagger}$
}

\author{
L. H. Tagle, F. R. Diaz, and P. E. Riveros \\ Organic Synthesis Laboratory, Faculty of Chemistry, Catholic University of Chile, \\ P.O. Box 6177, Santiago, Chile
}

(Received January 13, 1986)

\begin{abstract}
Polythiocarbonates were synthesized from several diphenols and thiophosgene under phase transfer catalysis conditions, using quaternary ammonium and phosphonium salts and a crown ether as catalysts, and dichloromethane as solvent. Polymers were characterized by IR and ${ }^{1} \mathrm{H}$ NMR, and the molecular weights were estimated from inherent viscosity measurements. The influence of the catalysts and the structure of the diphenols were studied, it was found that both exert an important effect on the molecular weights. The yields were acceptable and higher than $75 \%$ in most cases.

KEY WORDS Polythiocarbonates / Phase Transfer Catalysis / Diphenols / Phase Transfer Catalysts /
\end{abstract}

In a previous paper ${ }^{1}$ we described a systematic study on the synthesis of the polythiocarbonate from bisphenol $\mathrm{A}$ and thiophosgene under phase transfer catalysis conditions, using several catalysts and solvents.

In that paper we analyzed the influence of the solvent and the nature of the catalyst, as well as several mode of thiophosgene addition (dropwise or in portions), concluding that the best solvent was dichloromethane, and the best mode of thiophosgene addition was in one portion. About the catalysts, several of them were effective to obtain high yields and molecular weights, especially tetrabutylammonium bromide and the crown ether dicyclohexane18-crown-6.

Continuing our work ${ }^{2}$ on the application of phase transfer catalysis to polymer synthesis, in this paper we describe polythiocarbonates syntheses from several diphenols $\left(4,4^{\prime}\right.$-dihydroxy-diphenyl-alkanes) and thiophosgene, using several catalysts and the conditions pre- viously described. ${ }^{1}$

\section{EXPERIMENTAL}

\section{Materials}

Diphenols were synthesized from phenol and the corresponding aldehyde or ketone according to the procedure described by McGreal et al. ${ }^{3}$ Thiophosgene and solvents (from Merck) were used without further purification. The following catalysts (from Fluka) were used: tetrabutylammonium bromide (TBAB), hexadecyltrimethylammonium bromide (HDTMAB), tributylhexadecylphosphonium bromide (TBHDPB), methyltrioctylammonium chloride (Aliquat 336), and crown ether dicyclohexane-18-crown-6 (DCH-18-C-6).

\section{Measurements}

The IR spectra were recorded on a Perkin Elmer 1310 spectrophotometer, the ${ }^{1} \mathrm{H}$ NMR on a $100 \mathrm{MHz}$ instrument (Varian XL-100),

\footnotetext{
+ For Part III, see ref 2.
} 
using $\mathrm{CDCl}_{3}$ as solvent and TMS as internal standard. Viscosimetric measurements were made in a Desreux-Bischoff ${ }^{4}$ type dilution viscosimeter in $\mathrm{CHCl}_{3}$ at $25^{\circ} \mathrm{C}$.

\section{Polymerizations}

In a typical polycondensation reaction, $5 \mathrm{~m}$ mol of the diphenol and $0.25 \mathrm{mmol}$ of the catalyst dissolved in $30 \mathrm{ml}$ of $1 \mathrm{M} \mathrm{NaOH}$ were mixed with $20 \mathrm{ml}$ of $\mathrm{CH}_{2} \mathrm{Cl}_{2}$. Then, $5 \mathrm{mmol}$ of thiophosgene dissolved in $15 \mathrm{ml}$ of $\mathrm{CH}_{2} \mathrm{Cl}_{2}$ were added at once. The mixture was stirred at $20^{\circ} \mathrm{C}$ for $2.5 \mathrm{~h}$. The organic layer was separated and poured into methanol. The precipitated polymer was filtered, washed with methanol, dried under vacuum at $40^{\circ} \mathrm{C}$, and then characterized by IR, ${ }^{1} \mathrm{H}$ NMR, and elemental analysis.

\section{RESULTS AND DISCUSSION}

Polythiocarbonates were obtained according to the following reaction, and the structures were confirmed by IR and

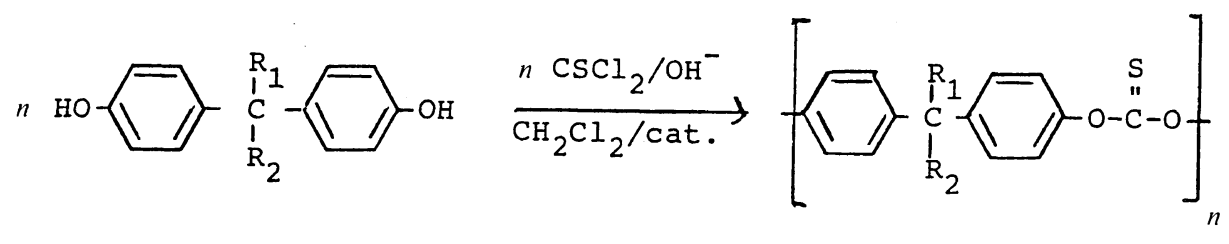

${ }^{1} \mathrm{H}$ NMR spectroscopy and elemental analysis. All the polymers show the absorption at 1200 $\mathrm{cm}^{-1}$ corresponding to the stretching of the $\mathrm{C}=\mathrm{S}$ group. The ${ }^{1} \mathrm{H} \mathrm{NMR}$ signals and the elemental analysis are shown in Table I, and are in accordance with the proposed structures.

Table II shows the yields and inherent viscosities of the polythiocarbonates obtained with and without catalysts. Without a catalyst, low values of $\eta_{\text {inh }}$ were observed although the yields were between 50 and $75 \%$, probably due to an interfacial polycondensation between thiophosgene dissolved in the organic phase and the alkaline diphenolate in the aqueous phase.

With the crown ether DCH-18-C-6, $\mathrm{KOH}$ was used because the $\mathrm{K}^{+}$ion has the adequate size to form a cationic complex. Although reported to be effective in polysulfonate ${ }^{5}$ and polythiocarbonate from bisphenol $\mathrm{A}^{1}$ syntheses, with these diphenols it was not effective, and the yields and $\eta_{\text {inh }}$ can be explained by interfacial polycondensation. Probably with this catalyst, activation of the dianion is rapidly suppressed by traces of water in the medi- um, bcause crown ethers tend to carry water into solvents even as nonpolar as chloroform $^{6.7}$; the anion solvating reduces the nucleophilicity.

TBHDPB was also ineffective, probably because this catalyst has a lipophilic character, even more when it must transfer very lipophilic dianions as that with the naphtyl group (polymer 6). Hydrolysis of thiocarbonyl chloride end groups in the polymeric chains can be favored and, as a consequence, a decrease in the molecular weight may be expected. Something similar would be obtained if water molecules were transferred to the organic phase, even more so in an alkaline medium as in the present case. $^{8}$

Aliquat was the best catalyst with several diphenols. The three $\mathrm{C}_{8}$ chains bonded to the $\mathrm{N}$ atom confer an adequate separation to the ionic pair, which in form confers high reactivity on the organic phase. Furthermore, Aliquat is the only catalyst with $\mathrm{Cl}^{-}$as counterion, which is exchanged more easily than $\mathrm{Br}^{-}$, the counterion of the other catalysts. Moreover, with this catalyst, a tendency can be noted for the inherent viscosities to decrease 
Table I. Elemental analysis and ${ }^{1} \mathrm{H}$ NMR signals of polythiocarbonates
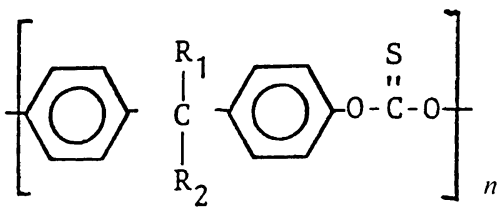

\begin{tabular}{|c|c|c|c|c|c|}
\hline & \multirow{2}{*}{$\mathrm{R}_{1}$} & \multirow{2}{*}{$\mathrm{R}_{2}$} & \multicolumn{2}{|c|}{ Elemental analysis $/ \%$} & \multirow{2}{*}{${ }^{1} \mathrm{H}$ NMR Signals, $\delta / \mathrm{ppm}$} \\
\hline & & & Found & Calcd & \\
\hline 1 & $\mathrm{H}$ & $\mathrm{CH}_{3}$ & $\begin{array}{lr}\mathrm{C}: & 70.35 \\
\mathrm{H}: & 5.03\end{array}$ & $\begin{array}{r}70.31 \\
4.69\end{array}$ & $\begin{array}{l}1.66\left(\mathrm{~d}, \mathrm{CH}_{3}\right) ; 4.24(\mathrm{c}, \mathrm{CH}) \\
7.24(\mathrm{c}, \mathrm{Ar}-\mathrm{H})\end{array}$ \\
\hline 2 & $\mathrm{H}$ & $\mathrm{C}_{2} \mathrm{H}_{5}$ & $\begin{array}{lr}C: & 71.55 \\
H: & 5.95\end{array}$ & $\begin{array}{r}71.11 \\
5.19\end{array}$ & $\begin{array}{l}0.9\left(\mathrm{t}, \mathrm{CH}_{3}\right) ; 2.08\left(\mathrm{~m}, \mathrm{CH}_{2}\right) \\
3.86(\mathrm{t}, \mathrm{CH}) ; 7.22(\mathrm{c}, \mathrm{Ar}-\mathrm{H})\end{array}$ \\
\hline 3 & $\mathrm{H}$ & $\mathrm{C}_{3} \mathrm{H}_{7}$ & $\begin{array}{l}C: \quad 71.28 \\
H: \quad 6.02\end{array}$ & $\begin{array}{r}71.83 \\
5.63\end{array}$ & $\begin{array}{l}0.95\left(\mathrm{t}, \mathrm{CH}_{3}\right) ; 1.28\left(\mathrm{~m}, \mathrm{CH}_{2}\right) \\
2.00\left(\mathrm{c}, \mathrm{CH}_{2}\right) ; 3.96(\mathrm{t}, \mathrm{CH}) \\
7.26(\mathrm{c}, \mathrm{Ar}-\mathrm{H})\end{array}$ \\
\hline 4 & $\mathrm{H}$ & iso- $\mathrm{C}_{3} \mathrm{H}_{7}$ & $\begin{array}{lr}\mathrm{C}: & 70.64 \\
\mathrm{H}: & 5.36\end{array}$ & $\begin{array}{r}71.83 \\
5.63\end{array}$ & $\begin{array}{l}0.89\left(\mathrm{~d}, \mathrm{CH}_{3}\right) ; 2.46(\mathrm{~m}, \mathrm{CH}) \\
3.40(\mathrm{~d}, \mathrm{CH}) ; 7.24(\mathrm{c}, \mathrm{Ar}-\mathrm{H})\end{array}$ \\
\hline 5 & $\mathrm{H}$ & $\mathrm{CH}\left(\mathrm{C}_{2} \mathrm{H}_{5}\right)_{2}$ & $\begin{array}{lr}C: & 72.04 \\
H: & 6.70\end{array}$ & $\begin{array}{r}72.48 \\
6.04\end{array}$ & $\begin{array}{l}0.91\left(\mathrm{t}, \mathrm{CH}_{3}\right) ; 1.40\left(\mathrm{~m}, \mathrm{CH}_{2}\right) \\
2.24(\mathrm{~m}, \mathrm{CH}) ; 3.70(\mathrm{~m}, \mathrm{CH}) \\
7.25(\mathrm{c}, \mathrm{Ar}-\mathrm{H})\end{array}$ \\
\hline 6 & $\mathrm{H}$ & $\mathrm{C}_{10} \mathrm{H}_{7}$ & $\begin{array}{lr}\mathrm{C}: & 78.15 \\
\mathrm{H}: & 5.05\end{array}$ & $\begin{array}{r}78.26 \\
4.35\end{array}$ & $6.35(\mathrm{~s}, \mathrm{CH}) ; 7.02-7.95(\mathrm{Ar}-\mathrm{H})$ \\
\hline 7 & $\mathrm{CH}_{3}$ & $\mathrm{C}_{2} \mathrm{H}_{5}$ & $\begin{array}{l}\mathrm{C}: \\
\mathrm{H}: \quad 5.65\end{array}$ & $\begin{array}{r}71.83 \\
5.63\end{array}$ & $\begin{array}{l}0.76\left(\mathrm{t}, \mathrm{CH}_{3}\right) ; 1.66\left(\mathrm{~s}, \mathrm{CH}_{3}\right) \\
2.16\left(\mathrm{c}, \mathrm{CH}_{2}\right) ; 7.22(\mathrm{c}, \mathrm{Ar}-\mathrm{H})\end{array}$ \\
\hline 8 & $\mathrm{CH}_{3}$ & $\mathrm{CH}_{2} \mathrm{CH}\left(\mathrm{CH}_{3}\right)_{2}$ & $\begin{array}{l}\mathrm{C}: \\
\mathrm{H}: \quad 6.69\end{array}$ & $\begin{array}{r}73.08 \\
6.41\end{array}$ & $\begin{array}{l}0.76\left(\mathrm{~d}, \mathrm{CH}_{3}\right) ; 1.43(\mathrm{~m}, \mathrm{CH}) \\
1.7\left(\mathrm{~s}, \mathrm{CH}_{3}\right) ; 2.08\left(\mathrm{~d}, \mathrm{CH}_{2}\right) \\
7.22(\mathrm{c}, \mathrm{Ar}-\mathrm{H})\end{array}$ \\
\hline 9 & $\left(\mathrm{CH}_{2}\right)_{5}$ & & 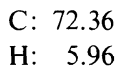 & $\begin{array}{r}73.55 \\
5.81\end{array}$ & $\begin{array}{l}1.56-2.30\left(\mathrm{~m}, \mathrm{CH}_{2}\right) \\
7.25(\mathrm{c}, \mathrm{Ar}-\mathrm{H})\end{array}$ \\
\hline 10 & $\left(\mathrm{CH}_{2}\right)_{2}$ & $\left.\mathrm{CH}_{3}\right)\left(\mathrm{CH}_{2}\right)_{2}$ & $\begin{array}{lr}\mathrm{C}: & 74.51 \\
\mathrm{H}: & 6.56\end{array}$ & $\begin{array}{r}74.07 \\
6.17\end{array}$ & $\begin{array}{l}0.91\left(\mathrm{~d}, \mathrm{CH}_{3}\right) ; 1.20-2.76 \\
\left(\mathrm{~m}, \mathrm{CH}_{2}\right) ; 6.93-7.40(\mathrm{~m}, \mathrm{Ar}-\mathrm{H})\end{array}$ \\
\hline 11 & $\mathrm{CH}_{3}$ & $\mathrm{C}_{6} \mathrm{H}_{5}$ & $\begin{array}{l}\mathrm{C}: 75.85 \\
\mathrm{H}: \quad 5.01\end{array}$ & $\begin{array}{r}75.90 \\
4.82\end{array}$ & $2.22\left(\mathrm{~s}, \mathrm{CH}_{3}\right) ; 7.20(\mathrm{~m}, \mathrm{Ar}-\mathrm{H})$ \\
\hline 12 & $\mathrm{C}_{2} \mathrm{H}_{5}$ & $\mathrm{C}_{6} \mathrm{H}_{5}$ & $\begin{array}{l}\text { C: } 75.75 \\
\mathrm{H}: \quad 4.90\end{array}$ & $\begin{array}{r}76.30 \\
5.20\end{array}$ & $\begin{array}{l}0.80\left(\mathrm{t}, \mathrm{CH}_{3}\right) ; 2.64\left(\mathrm{c}, \mathrm{CH}_{2}\right) \\
7.22(\mathrm{c}, \mathrm{Ar}-\mathrm{H})\end{array}$ \\
\hline
\end{tabular}

when the lipophilic character of the diphenol increases. Aliquat is ineffective with the diphenol with a naphtyl group (polymer 6), in which there are only an interfacial polycondensation process, probably due to the lipophilic character of this catalyst. ${ }^{9}$ This effect is 
Table II. Yields and inherent viscosities of polythiocarbonates

\begin{tabular}{|c|c|c|c|c|c|c|c|c|c|c|c|c|}
\hline \multirow{3}{*}{ Polymer ${ }^{\mathrm{a}}$} & \multicolumn{2}{|c|}{ TBAB } & \multicolumn{2}{|c|}{ TBHDPB } & \multicolumn{2}{|c|}{ HDTMAB } & \multicolumn{2}{|c|}{ Aliquat } & \multicolumn{2}{|c|}{ DCH-18-C-6 } & \multicolumn{2}{|c|}{ None } \\
\hline & Yield & & Yield & & Yield & & Yield & & Yield & & Yield & \\
\hline & $\%$ & & $\%$ & & $\%$ & & $\%$ & & $\%$ & & $\%$ & \\
\hline 1 & 88 & 0.45 & 92 & 0.20 & 85 & 0.34 & 89 & 0.42 & 88 & 0.22 & 77 & 0.22 \\
\hline 2 & 85 & 0.30 & 85 & 0.20 & 85 & 0.42 & 85 & 0.60 & 78 & 0.18 & 56 & 0.11 \\
\hline 3 & 82 & 0.48 & 89 & 0.19 & 82 & 0.13 & 71 & 0.40 & 68 & 0.17 & 57 & 0.13 \\
\hline 4 & 84 & 0.35 & 83 & 0.33 & 80 & 0.18 & 89 & 0.28 & 71 & 0.28 & 42 & 0.12 \\
\hline 5 & 89 & 0.23 & 82 & 0.24 & 86 & 0.14 & 93 & 0.28 & 75 & 0.20 & 50 & 0.13 \\
\hline 6 & 78 & 0.11 & 78 & 0.12 & 68 & 0.11 & 54 & 0.12 & 53 & 0.10 & 58 & 0.08 \\
\hline 7 & 67 & 0.16 & 94 & 0.15 & 96 & 0.43 & 99 & 0.62 & 87 & 0.14 & 75 & 0.17 \\
\hline 8 & 74 & 0.15 & 84 & 0.18 & 82 & 0.34 & 83 & 0.55 & 80 & 0.17 & 71 & 0.17 \\
\hline 9 & 84 & 0.14 & 90 & 0.23 & 87 & 0.28 & 92 & 0.45 & 91 & 0.14 & 68 & 0.11 \\
\hline 10 & 92 & 0.29 & 87 & 0.33 & 86 & 0.21 & 86 & 0.28 & 90 & 0.24 & 56 & 0.16 \\
\hline 11 & 87 & 0.14 & 90 & 0.16 & 83 & 0.21 & 94 & 0.68 & 80 & 0.23 & 59 & 0.09 \\
\hline 12 & 94 & 0.20 & 93 & 0.24 & 95 & 0.20 & 95 & 0.26 & 75 & 0.13 & 81 & 0.14 \\
\hline
\end{tabular}

a See Table I.

b $\mathrm{dlg}^{-1}$; in $\mathrm{CHCl}_{3}$ at $25^{\circ} \mathrm{C}\left(c=0.5 \mathrm{~g} \mathrm{~d}^{-1}\right)$.

c $\mathrm{KOH}, 1 \mathrm{M}$.

greater with the catalysts that are more effective.

TBAB presents an intermediate behavior, and also the $\mathrm{C}_{4}$ chains provide adequate separation for the ionic pair.

HDTMAB, by structure, one long lipophilic chain and three methyl groups, has the characteristics of a micellar agent ${ }^{10}$; a process of this kind is impossible to rule out. However, Yamazaki and Imai $^{11}$ have demonstrated in polyether synthesis that the mechanism of polymerization is the same with HDTMAB and $T B A B$, which is not a micellar agent. HDTMAB presented a relatively poor behavior with these diphenols.

In general, it seems the limiting step of the polymerization process is the transfer of the dianion rather than the reaction in the organic phase, because the thiophosgene is highly reactive. Therefore the nature of the catalyst is an important factor.

Acknowledgements. The author acknowl- edge the support for this research by "Dirección de Investigación de la Universidad Católica de Chile" (D.I.U.C.) through grant 26/83.

\section{REFERENCES}

1. L. H. Tagle, F. R. Diaz, J. C. Vega, and P. F. Alquinta, Makromol. Chem., 186, 915 (1985).

2. L. H. Tagle, F. R. Diaz, M. P. De La Maza, and J. C. Vega, J. Polym. Sci., Polym. Chem. Ed., in press.

3. M. E. McGreal, U. Niederl, and J. B. Niederl, J. Am. Chem. Soc., 61, 345 (1939).

4. V. Desreux and F. Bischoff, Bull. Soc. Chim. Belg., 59, 93 (1950).

5. Y. Imai, J. Macromol. Sci., Chem., A15, 833 (1981).

6. E. U. Dehmlow and S. S. Dehmlow, "Phase Transfer Catalysis" Monographs in Modern Chemistry, Vol. 11, Verlag Chemie, Weinheim, 1980, p. 20.

7. F. de Song, D. N. Reinhoudt, and C. J. Smit, Tetrahedron Lett., 1371, 1375 (1976).

8. C. M. Starks and C. Liotta, "Phase Transder Catalysis. Principles and Techniques," Academic Press, New York, 1978, p 49.

9. Reference 6, p 9.

10. Reference 8, p 42 .

11. N. Yamazaki and Y. Imai, Polym. J., 17, 377 (1985). 